\title{
Springer
}

\section{Visualization of DAS28, SDAI and CDAI: the magic carpets \\ of rheumatoid arthritis}

\begin{tabular}{|r|l|}
\hline Journal: & Clinical Rheumatology \\
\hline Manuscript ID: & Draft \\
\hline Manuscript Type: & Original Article \\
\hline Date Submitted by the Author: & $\mathrm{n} / \mathrm{a}$ \\
\hline Complete List of Authors: & $\begin{array}{l}\text { Futó, Gábor; University of Debrecen Medical and Health Sciences Center, } \\
\text { Institute of Medicine, Department of Rheumatology } \\
\text { Somogyi, Attila; University of Debrecen Medical and Health Sciences } \\
\text { Center, School of Medicine } \\
\text { Szekanecz, Zoltán; University of Debrecen Medical and Health Sciences } \\
\text { Center, Institute of Medicine, Department of Rheumatology }\end{array}$ \\
\hline Keywords: & rheumatoid arthritis, disease activity, DAS, DAS28, CDAI, SDAI \\
\hline &
\end{tabular}




\title{
Visualization of DAS28, SDAI and CDAI: the magic carpets of
} rheumatoid arthritis

\author{
Gábor Futó $^{1,2}$, Attila Somogyi $^{2}$, Zoltán Szekanecz $^{1}$ \\ ${ }^{1}$ Department of Rheumatology, Institute of Medicine, and ${ }^{2}$ School of Medicine, University of \\ Debrecen Medical and Health Science Center, Debrecen, Hungary
}

Running title: Disease activity indices in rheumatoid arthritis

Key words: rheumatoid arthritis / disease activity / DAS28 / SDAI / CDAI

Please address correspondence to:

Zoltán Szekanecz, MD, PhD; Department of Rheumatology, Institute of Medicine, University of Debrecen, Medical and Health Sciences Center, Hungary

Nagyerdei str 98, Debrecen, 4032, Hungary

E-mail: szekanecz.zoltan@med.unideb.hu 


\begin{abstract}
Objective. There has been continuous debate regarding the applicability of various composite measures for the assessment of disease activity in rheumatoid arthritis (RA). In order to further dissect this issue, we numerically and graphically modeled DAS28, SDAI and CDAI by 3-dimensional plotting. We wished to graphically visualize the relative contribution of various elements in the three activity indices to each other.

Methods. We calculated DAS28 (3-variable), SDAI and CDAI by the standard equations. We plotted 3-dimensional (3D) "carpets" showing all combinations of the corresponding variables yielding to DAS28 $=5.1, \mathrm{DAS} 28=3.2, \mathrm{DAS} 28=2.6, \mathrm{SDAI}=26, \mathrm{SDAI}=11$ and $\mathrm{SDAI}=3.3 . \mathrm{We}$ also plotted the 3D carpet for CDAI.

Results: In patients with high or moderate disease activity, erythrocyte sedimentation rate (ESR) or C-reactive protein (CRP) were not major confounding factors when calculating DAS28 and SDAI, respectively. In contrast, ESR and CRP highly overshadowed changes in joint counts and global assessments in patients with low disease activity (LDA) or in those in remission. No reliable assessment of LDA can be performed in cases where ESR $>54 \mathrm{~mm} / \mathrm{h}$ or CRP $>20 \mathrm{mg} / \mathrm{dl}$. Similarly, remission cannot be determined if $\mathrm{ESR}>19 \mathrm{~mm} / \mathrm{h}$ or $\mathrm{CRP}>5 \mathrm{mg} / \mathrm{dl}$. As CDAI does not include acute phase reactants, CDAI may be a useful tool even in states of remission or LDA.
\end{abstract}

Conclusions: Our results suggest that acute phase reactnats are indeed major confounding factors and should be omitted when assessing RA disease activity, at least in special cases. 


\section{Introduction}

Rheumatoid arthritis (RA) is a progressive inflammatory rheumatic disease, which may lead to joint destruction and disability. Thus, early diagnosis, close follow-up and early, effective treatment are imperative in order to prevent structural damage and functional impairment $(1,2)$. Various instruments have been developed in order to accurately determine disease activity of RA at any given timepoint during the disease course (2). Among disease activity indices, the 28-joint disease activity scale (DAS28) has long been used in the daily practice, as well as in clinical trials. The 3-variable DAS28 (DAS28-V3) includes erythrocyte sedimentation rate (ESR), swollen (SJC) and tender joint counts (TJC) determined in 28 designated joints, while the 4-variable version (DAS28-V4) also includes patient-determined global health $(\mathrm{GH})$ assessed on a 100-mm visual analogue scale (VAS) (2-4). However, the somewhat complicated formula requires the use of special calculators or computer softwares (Table 1). Therefore a simplified disease activity index (SDAI) has later been developed by simply adding five variables including SJC, TJC in 28 joints, $\mathrm{C}$ reactive protein level (CRP, $\mathrm{mg} / \mathrm{dL}$ ), as well as patient- (PGA) and evaluator-determined global disease activity (EGA) assessed by 10-cm VAS (5-7). Some further studies suggested that the determination of acute phase reactants (APR), such as ESR or CRP add little to the other four parameters when assessing SDAI (8). Therefore an even more simple clinical disease activity index (CDAI) has been introduced by omitting CRP and just adding the other four variables, SJC, TJC, PGA and $\operatorname{EGA}(5,6,9)$. The elements of these composite indices and the calculation formulas are included in Table 1.

It has become clear from routine clinical practice that the "APR issue" may have another important aspect. Apart from not giving extra value during the determination of disease activity (8), ESR and CRP may even overshadow the other clinical parameters. Indeed, APRs reflect systemic inflammation and, in most patients, reflect disease activity. 
However, we often see patients with LDA of RA, yet highly elevated ESR or CRP levels due to other confounding factors, such as infections, paraproteins or simply high immunoglobulin or total protein levels. On the other hand, some patients may have highly destructive RA despite "low-grade" inflammation. In such conditions, very low or very high APR levels may override the influence of other clinical variables when determining DAS28 or SDAI. As very recently published by Smolen and Aletaha (10), the determination of response to biologics may be highly influenced by APRs as much better reponse to tocilizumab was observed using DAS28 in comparison to CDAI.

In order to further dissect this issue, we numerically and graphically modeled DAS28, SDAI and CDAI by 3-dimensional plotting. Our aim was to compare and graphically visualize the relative contribution of various elements in the three activity indices to each other. Our results suggest that APRs are indeed major confounding factors and should be omitted when assessing RA disease activity, at least in special cases.

\section{Methods}

DAS28-V3 graphs

We used the 3-variable version of DAS28. DAS28-V3 was calculated by using the standard equation of DAS28 $=(0.56 \times \sqrt{ }-\mathrm{TJC}+0.28 \times \sqrt{-} \mathrm{SJC}+0.7 \times \ln \mathrm{ESR}) \times 1.08+0.16$ According to the definition of high, low disease activity and remission (Table 1), DAS28 = 5.1, 3.2 and 2.6, respectively, were calculated using all possible TJC (0-28), SJC (0-28) and ESR (0-100 mm/h) values. Then, three-dimensional (3D) graphs were plotted with TJC, ESR and SJC on the $\mathrm{X}, \mathrm{Y}$ and $\mathrm{Z}$ axes, respectively, expressing DAS28 values of 5.1 (Figure 
1a,B,C), 3.2 (Figure 2A,B,C) and 2.6 (Figure 3A,B,C). 3D "carpets" are presented as snapshots taken from different views.

SDAI graphs

SDAI was calculated by the standard equation of $\mathrm{SDAI}=\mathrm{TJC}+\mathrm{SJC}+\mathrm{PGA}+\mathrm{EGA}+$ CRP, assessing 28-jount counts (Table 1). As five variables cannot be plotted in 3D graphs, TJC and SJC were added yielding to a composite joint score (TJC+SJC: 0-56), PGA and EGA were also added yielding to a composite assessment score (PGA+EGA: 0-20) and these two composite scores were plotted against CRP. Now we ended up with only 3 variables. As the SDAI limits between high/moderate, moderate/LDA and LDA/remission are 26, 11 and 3.3, respectively (Table 1), we plotted three 3D graphs expressing SDAI values of 26 (Figure 4), 11 (Figure 5) and 3.3 (Figure 6). In these "carpets", TJC+SJC, CRP and PGA+EGA were plotted on the $\mathrm{X}, \mathrm{Y}$ and $\mathrm{Z}$ axes, respectively.

\section{CDAI graphs}

CDAI was calculated by the standard formula of CDAI $=\mathrm{TJC}+\mathrm{SJC}+\mathrm{PGA}+\mathrm{EGA}$ by assessing 28 joints (Table 1). As 4 variables cannot be plotted in 3D graphs and we also wished to compare SDAI and CDAI graphs, we, similarly to what was performed in the case of SDAI, we again formed two composite indices by adding TJC+SJC and also PGA+EGA. This yielded to only two variables so in this situation TJC+SJC and PGA+EGA were plotted on $\mathrm{X}$ and $\mathrm{Z}$ axis, and all CDAI values could be visualized in on the $\mathrm{Y}$ axis of $3 \mathrm{D}$ carpets (Figure 7A,B). 


\section{Results}

The DAS28 carpets

In Figures 1, 2 and 3 carpets of DAS28=5.1, 3.2 and 2.6 are visualized as snapshots taken from three different views (A,B,C), respectively. The DAS28=5.1 carpet (Figure 1A-C) reflects all possibilities, how high disease activity can be presented. When looking at some examples, on one hand, taken the maximum SJC and TJC values of 28 each, ESR $=1.2 \mathrm{~mm} / \mathrm{h}$ indicating that DAS28 $=5.1$ can be reached if ESR is above $1 \mathrm{~mm} / \mathrm{h}$. In addition, patients with 0 or 1 tender and/or swollen joints would require ESR $>200 \mathrm{~mm} / \mathrm{h}$ to reach DAS28=5.1, which is defitely not realistic. Thus, in the case of DAS28=5.1, ESR is not a major confounding factor.

When the carpet of DAS28 $=3.2$ is plotted (Figure 2A-C), it is clear from the examples that zero TJC and SJC correspond with ESR=54 mm/h. Thus, patients with ESR $>54 \mathrm{~mm} / \mathrm{h}$ may never reach LDA. As some patients may exert higher ESR despite of no or very few tender and swollen joints, ESR may be a confounding factor when calculating DAS28 and may override the weight of the other two variables.

Similarly, when the carpet of DAS28 $=2.6$ is visualized (Figure $3 \mathrm{~A}-\mathrm{C}$ ), zero TJC and SJC correspond with $\mathrm{ESR}=19 \mathrm{~mm} / \mathrm{h}$. Thus, RA patients with $\mathrm{ESR}>19 \mathrm{~mm} / \mathrm{h}$ would never reach the state of remission.

The SDAI carpets

In Figures 4, 5 and 6, carpets of $\mathrm{SDAI}=26, \mathrm{SDAI}=11$ and $\mathrm{SDAI}=3.3$ are visualized as snapshots, respectively. The SDAI=26 carpet (Figure 4) reflects all possibilities, how high 
disease activity can be reached. If SJC+TJC or PGA+EGA sums are below 26, CRP is positive. In the case of cutoff between moderate and low disease activity (SDAI=11), most of the carpet is "on the floor", only TJC+SJC or PGA+EGA sums below 11 would yield positive CRP values (Figure 5). As for remission ( $\mathrm{SDAI}=3.3$ ), CRP must be $3.3 \mathrm{mg} / \mathrm{dl}$ or lower that yields to an almost flat graph. Both the TJC+SJC and the PGA+EGA sums must be $<3$, otherwise CRP would yield negative value (Figure 6). Thus, in the case of relatively high joint and/or assessment scores ( $>26$ ), high disease activity can easily be reached, irrespective of CRP (Figure 4). In contrast, when the carpets of $\mathrm{SDAI}=11$ and $\mathrm{SDAI}=3.3$ are plotted (Figures 5 and 6), almost the whole carpet is "on the floor". In these cases, CRP cannot be more than $11 \mathrm{mg} / \mathrm{dl}$ or $3.3 \mathrm{mg} / \mathrm{dl}$, respectively, otherwise CRP would be a confounding factor when calculating SDAI and may override the weight of the other four variables. In other words, patiernts with $\mathrm{CRP}>11 \mathrm{mg} / \mathrm{dl}$ or with $\mathrm{CRP}>3.3 \mathrm{mg} / \mathrm{dl}$ could never show SDAIdetermined LDA or remission, respectively (Figure 5 and 6).

\section{The CDAI carpets}

In Figure 7 (A and B), CDAI values are plotted on the $\mathrm{Y}$ axis against composite joint ( $\mathrm{X}$ axis) and assessment scores ( $\mathrm{Z}$ axis) formed similarly to SDAI visualization. CDAI carpets are visualized as snapshots taken from two different views (A,B). CDAI does not include CRP or ESR and is a simple sum of SJC+TJC+EGA+PGA. Thus, the calculation of CDAI is solely based on joint scores, as well as patient's and doctor's general assessments. As seen in Figure 7, there is no "carpet-on-floor" area indicating that CDAI is closely and linearly related with either joint counts or general assessments. Therefore, moderate disease activity $(\mathrm{CDAI} \leq 22)$, low disease activity $(\mathrm{CDAI} \leq 10)$ or remission $(\mathrm{CDAI} \leq 2.8)$ can be calculated upon any combination of the four variables, independent of any other confounding factors. Indeed, 
a mean variable value of $5.5,2.5$ and 0.7 or less are required to reach moderate, low disease activity or remission, respectively.

\section{Discussion}

There has been continuous debate regarding the comparison and practical use of three different disease activity composite indices, DAS28, SDAI and CDAI in RA. In 2005, Aletaha et al (8) proposed that APRs added little to composite indices. This led to the development of CDAI, an index not containing ESR or CRP $(6,11,12)$.

As most published papers presented calculations, we wished to visualize the distribution of various components in the three composite indices by drawing 3-dimensional “carpets" and by also presenting some examples in tables.

Our data confirm that while APRs may be useful when calculating DAS28 or SDAI in RA patients with high or moderate disease activity, ESR and/or CRP may be confounders of these calculations in patients with low disease activity or in those in remission. When using DAS28, ESR values $>54 \mathrm{~mm} / \mathrm{h}$ and $>19 \mathrm{~mm} / \mathrm{h}$ or, similarly, when calculating SDAI, CRP values $>11 \mathrm{mg} / \mathrm{dl}$ and $>3.3 \mathrm{mg} / \mathrm{dl}$ make the respective determination of LDA and remission impossible. In contrast, CDAI carpets indicate very good correlations of RAQ disease activity with joint scores, as well as patient- and doctor-determined measures without the confounding effects of APRs.

Some groups have also suggested that composite indices, such as DAS28 or SDAI may exert problems when used in remission or in LDA states (12-15). It is imperative to use proper tools to assess remission and LDA, as nowadays, according to the recent EULAR and treat-to-target recommendations, standard care, as well as clinical trials should target these disease states $(13,16-19)$. Furthermore, remission has also been associated with radiographic 
progression, especially in patients with residual joint swelling (20). Interestingly, as among biologics tocilizumab may have outstanding suppressive effects on APR production, APRcontaining composite measures may be very sensitive tools in this special setting (15).

Very recently, Bentley et al (11) developed a modified version of DAS28 (mDAS28) that also lacks APRs. Modified DAS28 showed substantial agreement with DAS28, SDAI amd CDAI.

In conclusion, our visualization of RA disease-activity "carpets" confirm that ESR and/or CRP may be significant confounding factors when assessing patients in remission or those with LDA.

\section{Figure legends}

Figure 1. Variability of three components (erythrocyte sedimentation rate [ESR], tender [TJC] and swollen jount counts [SJC]) leading to DAS28=5.1 (borderline between high and moderate disease activity) shown as a 3-dimensional "carpet" from three viewpoints $(1 \mathrm{~A}, 1 \mathrm{~B}, 1 \mathrm{C})$.

Figure 2. Variability of three components (erythrocyte sedimentation rate [ESR], tender [TJC] and swollen jount counts [SJC]) leading to DAS28=3.2 (borderline between moderate and low disease activity) shown as a 3-dimensional "carpet" from three viewpoints $(2 \mathrm{~A}, 2 \mathrm{~B}, 2 \mathrm{C})$.

Figure 3. Variability of three components (erythrocyte sedimentation rate [ESR], tender [TJC] and swollen jount counts [SJC]) leading to DAS28=2.6 (borderline between low disease activity and remission) shown as a 3-dimensional "carpet" from three viewpoints $(3 \mathrm{~A}, 3 \mathrm{~B}, 3 \mathrm{C})$.

Figure 4. Variability of three components (C reactive protein [CRP], tender [TJC] + swollen jount counts [SJC], patient's [PGA] + doctor's global assessment [EGA]) leading to SDAI=26 (borderline between high and moderate disease activity) shown as a 3-dimensional "carpet". 
Figure 5. Variability of three components (C reactive protein [CRP], tender [TJC] + swollen jount counts [SJC], patient's [PGA] + doctor's global assessment [EGA]) leading to SDAI=11 (borderline between moderate and low disease activity) shown as a 3-dimensional "carpet".

Figure 6. Variability of three components (C reactive protein [CRP], tender [TJC] + swollen jount counts $[\mathrm{SJC}]$, patient's [PGA] + doctor's global assessment [EGA]) leading to $\mathrm{SDAI}=3.3$ (borderline between low disease activity and remission) shown as a 3-dimensional "carpet".

Figure 7. Variability of tender [TJC] + swollen jount counts [SJC], patient's [PGA] + doctor's global assessment [EGA] and CDAI shown as a 3-dimensional "carpet" from two viewpoints (7A,7B). 


\section{Acknowledgements}

This work was supported by research grants ETT 315/2009 from the Medical Research Council of Hungary (Z.S.); OTKA K 105073 from the National Scientific Research Fund of Hungary (Z.S.), grants WS1695414 and WS1695450 by Pfizer (Z.S.), and by the TÁMOP 4.2.1/B-09/1/KONV-2010-0007 and 4.2.2.A-1/11/KONV-2012-0031 projects co-financed by the European Union and the European Social Fund (Z.S.) and the University of Debrecen Medical and Health Sciences Center Bridging Fund (Z.S.).

\section{None of the authors have any conflict of interest.}




\section{References}

1. Smolen JS, Landewe R, Breedveld FC, Dougados M, Emery P, Gaujoux-Viala C, et al. EULAR recommendations for the management of rheumatoid arthritis with synthetic and biological disease-modifying antirheumatic drugs. Ann Rheum Dis.

2. Aletaha D, Landewe R, Karonitsch T, Bathon J, Boers M, Bombardier C, et al. Reporting disease activity in clinical trials of patients with rheumatoid arthritis: EULAR/ACR collaborative recommendations. Arthritis Rheum 2008;59(10):1371-7.

3. van der Heijde DM, van 't Hof MA, van Riel PL, Theunisse LA, Lubberts EW, van Leeuwen MA, et al. Judging disease activity in clinical practice in rheumatoid arthritis: first step in the development of a disease activity score. Ann Rheum Dis 1990;49(11):916-20.

4. van der Heijde DM, van 't Hof M, van Riel PL, van de Putte LB. Development of a disease activity score based on judgment in clinical practice by rheumatologists. J Rheumatol 1993;20(3):579-81.

5. Aletaha D, Smolen J. The Simplified Disease Activity Index (SDAI) and the Clinical Disease Activity Index (CDAI): a review of their usefulness and validity in rheumatoid arthritis. Clin Exp Rheumatol 2005;23(5 Suppl 39):S100-8.

6. Aletaha D, Smolen JS. The Simplified Disease Activity Index (SDAI) and Clinical Disease Activity Index (CDAI) to monitor patients in standard clinical care. Best Pract Res Clin Rheumatol 2007;21(4):663-75.

7. Smolen JS, Breedveld FC, Schiff MH, Kalden JR, Emery P, Eberl G, et al. A simplified disease activity index for rheumatoid arthritis for use in clinical practice. Rheumatology (Oxford) 2003;42(2):244-57.

8. Aletaha D, Nell VP, Stamm T, Uffmann M, Pflugbeil S, Machold K, et al. Acute phase reactants add little to composite disease activity indices for rheumatoid arthritis: validation of a clinical activity score. Arthritis Res Ther 2005;7(4):R796-806.

9. Salaffi F, Cimmino MA, Leardini G, Gasparini S, Grassi W. Disease activity assessment of rheumatoid arthritis in daily practice: validity, internal consistency, reliability and congruency of the Disease Activity Score including 28 joints (DAS28) compared with the Clinical Disease Activity Index (CDAI). Clin Exp Rheumatol 2009;27(4):552-9.

10. Smolen JS, Aletaha D. Interleukin-6 receptor inhibition with tocilizumab and attainment of disease remission in rheumatoid arthritis: the role of acute-phase reactants. Arthritis Rheum 2011;63(1):43-52.

11. Bentley MJ, Greenberg JD, Reed GW. A modified rheumatoid arthritis disease activity score without acute-phase reactants (mDAS28) for epidemiological research. J Rheumatol;37(8):1607-14.

12. Rintelen B, Sautner J, Haindl PM, Andel I, Maktari A, Leeb BF. Comparison of three rheumatoid arthritis disease activity scores in clinical routine. Scand $J$ Rheumatol 2009;38(5):336-41.

13. Gaujoux-Viala C, Mouterde G, Baillet A, Claudepierre P, Fautrel B, Le Loet X, et al. Evaluating disease activity in rheumatoid arthritis: Which composite index is best? A systematic literature analysis of studies comparing the psychometric properties of the DAS, DAS28, SDAI and CDAI. Joint Bone Spine.

14. Bentley MJ, Reed GW. Simplified composite disease activity measures in rheumatoid arthritis: should they be used in standard care? Clin Exp Rheumatol 2008;26(2):358-66.

15. Smolen JS, Aletaha D. Interleukin-6 receptor inhibition with tocilizumab and attainment of disease remission in rheumatoid arthritis: the role of acute-phase reactants. Arthritis Rheum;63(1):43-52. 
16. Dougados M, Schmidely N, Le Bars M, Lafosse C, Schiff M, Smolen JS, et al. Evaluation of different methods used to assess disease activity in rheumatoid arthritis: analyses of abatacept clinical trial data. Ann Rheum Dis 2009;68(4):484-9.

17. Smolen JS, Landewe R, Breedveld FC, Dougados M, Emery P, Gaujoux-Viala C, et al. EULAR recommendations for the management of rheumatoid arthritis with synthetic and biological disease-modifying antirheumatic drugs. Ann Rheum Dis;69(6):964-75.

18. Burmester GR, Ferraccioli G, Flipo RM, Monteagudo-Saez I, Unnebrink K, Kary S, et al. Clinical remission and/or minimal disease activity in patients receiving adalimumab treatment in a multinational, open-label, twelve-week study. Arthritis Rheum 2008;59(1):3241.

19. Smolen JS, Aletaha D, Bijlsma JW, Breedveld FC, Boumpas D, Burmester G, et al. Treating rheumatoid arthritis to target: recommendations of an international task force. Ann Rheum Dis 2010;69(4):631-7.

20. Aletaha D, Smolen JS. Joint damage progresses in DAS28 remission and is driven by residual swollen joints. Arthritis Rheum. 
Table 1 Calculation and interpretation of DAS28-V3, SDAI and CDAI

\begin{tabular}{|l|l|c|c|c|c|}
\hline & \multicolumn{1}{|c|}{ Formula } & $\begin{array}{c}\text { High disease } \\
\text { activity }\end{array}$ & $\begin{array}{c}\text { Moderate } \\
\text { disease activity }\end{array}$ & $\begin{array}{c}\text { Low } \\
\text { disease } \\
\text { activity }\end{array}$ & Remission \\
\hline $\begin{array}{l}\text { DAS28- } \\
\text { V3 }\end{array}$ & $\begin{array}{l}(0.56 \times \sqrt{-} \text { TJC }+0.28 \times \sqrt{-} \mathrm{SJC}+ \\
0.7 \times \ln \mathrm{ESR}) \times 1.08+0.16\end{array}$ & $>5.1$ & $\leq 5.1$ & $\leq 3.2$ & $\leq 2.6$ \\
\hline SDAI(28) & TJC + SJC + PGA + EGA + CRP & $>26$ & $\leq 26$ & $\leq 11$ & $\leq 3.3$ \\
\hline CDAI(28) & TJC + SJC + PGA + EGA & $>22$ & $\leq 22$ & $\leq 10$ & $\leq 2.8$ \\
\hline
\end{tabular}




1
1
2
3
4




\section{Figure $1 \mathrm{~A}$}


DAS28 = 5.1

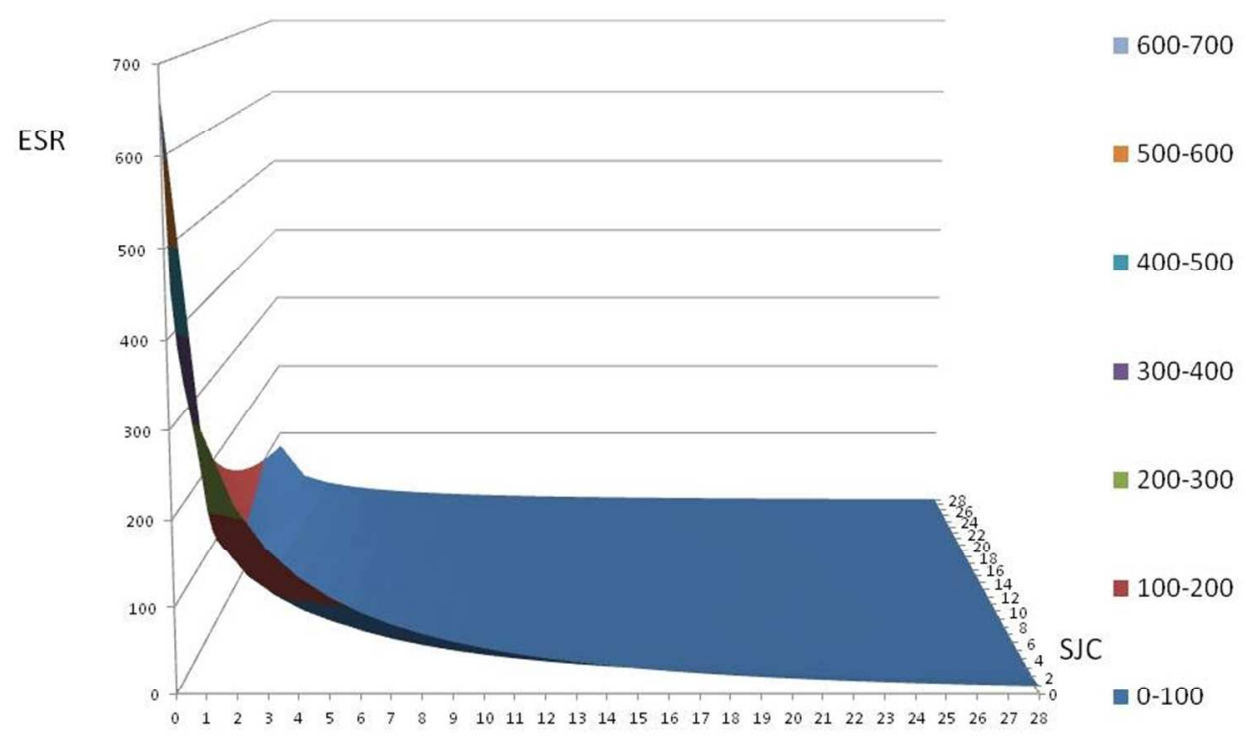

Figure 1B

254x190mm (96 x 96 DPI) 
DAS28 $=5.1$ 
DAS28 $=3.2$

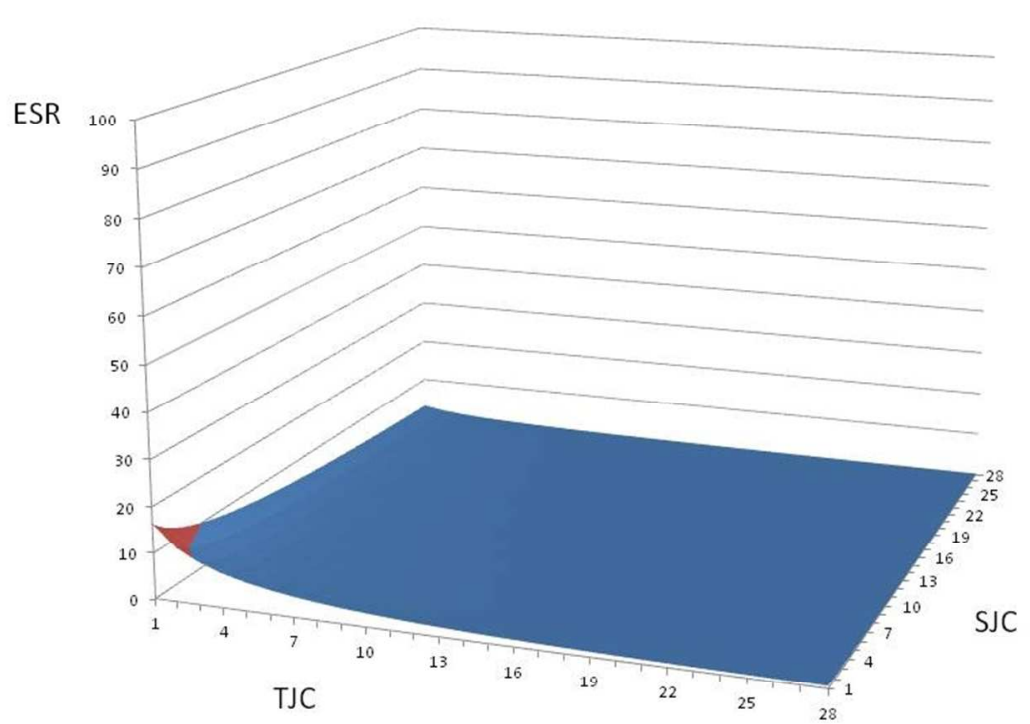

Figure 2A

$254 \times 190 \mathrm{~mm}(96 \times 96 \mathrm{DPI})$ 
DAS28 $=3.2$

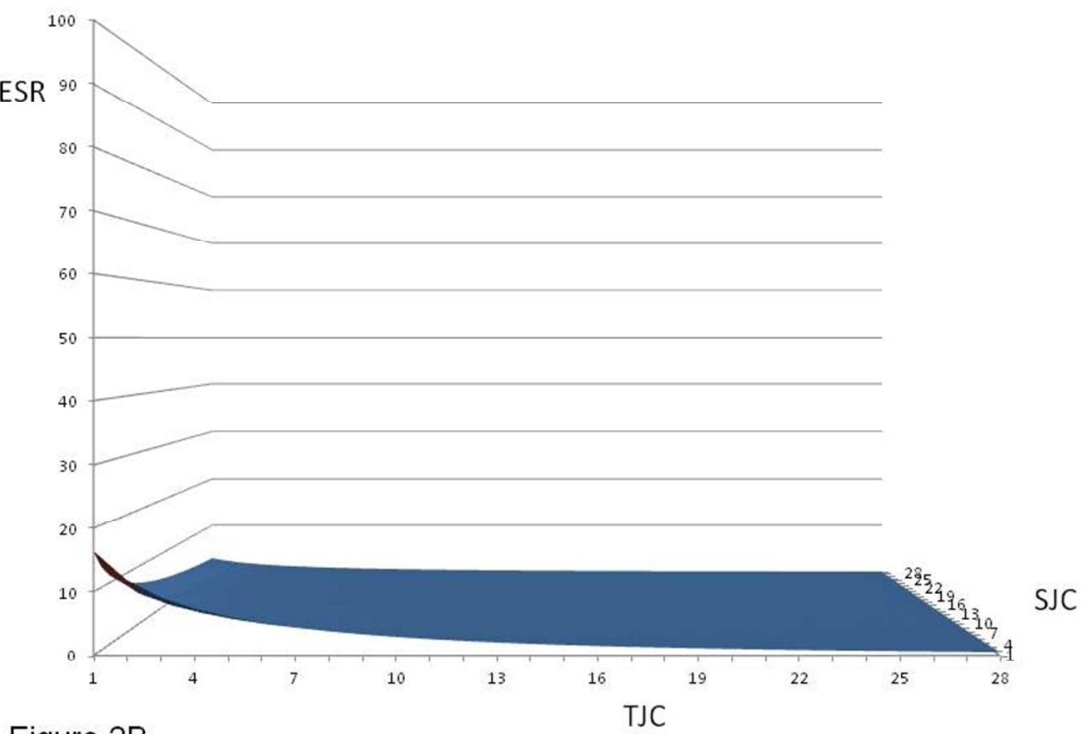

Figure 2B 


$$
\text { DAS28 }=3.2
$$

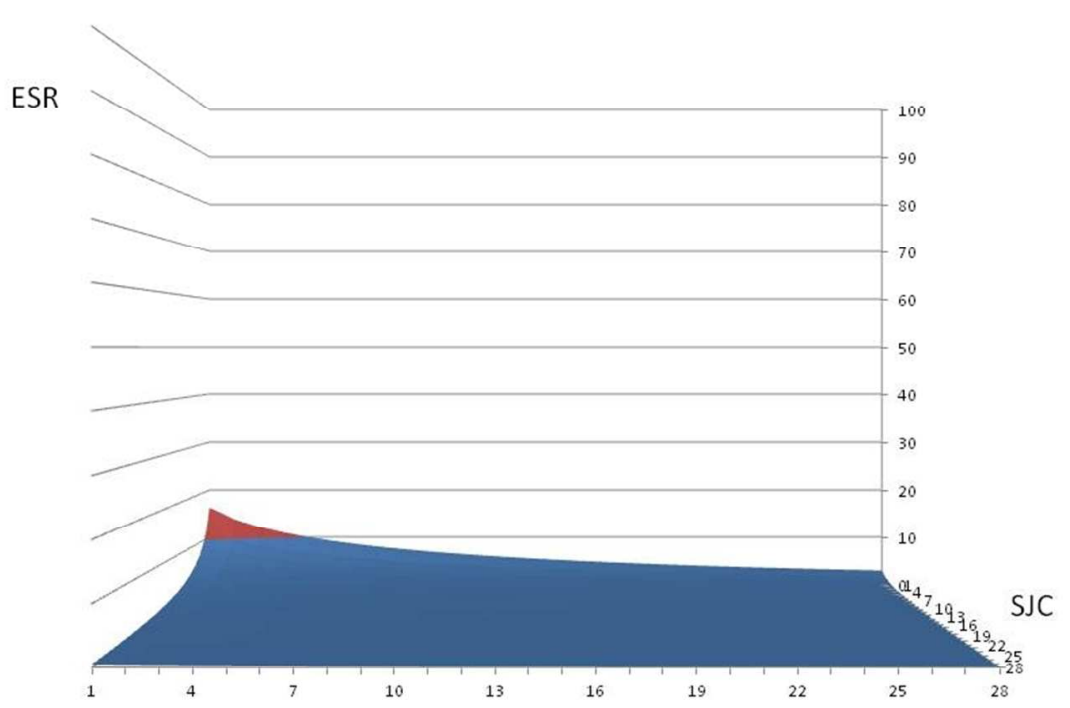

Figure 2C

TJC

254×190mm (96 × 96 DPI) 


\section{Figure $3 \mathrm{~A}$}

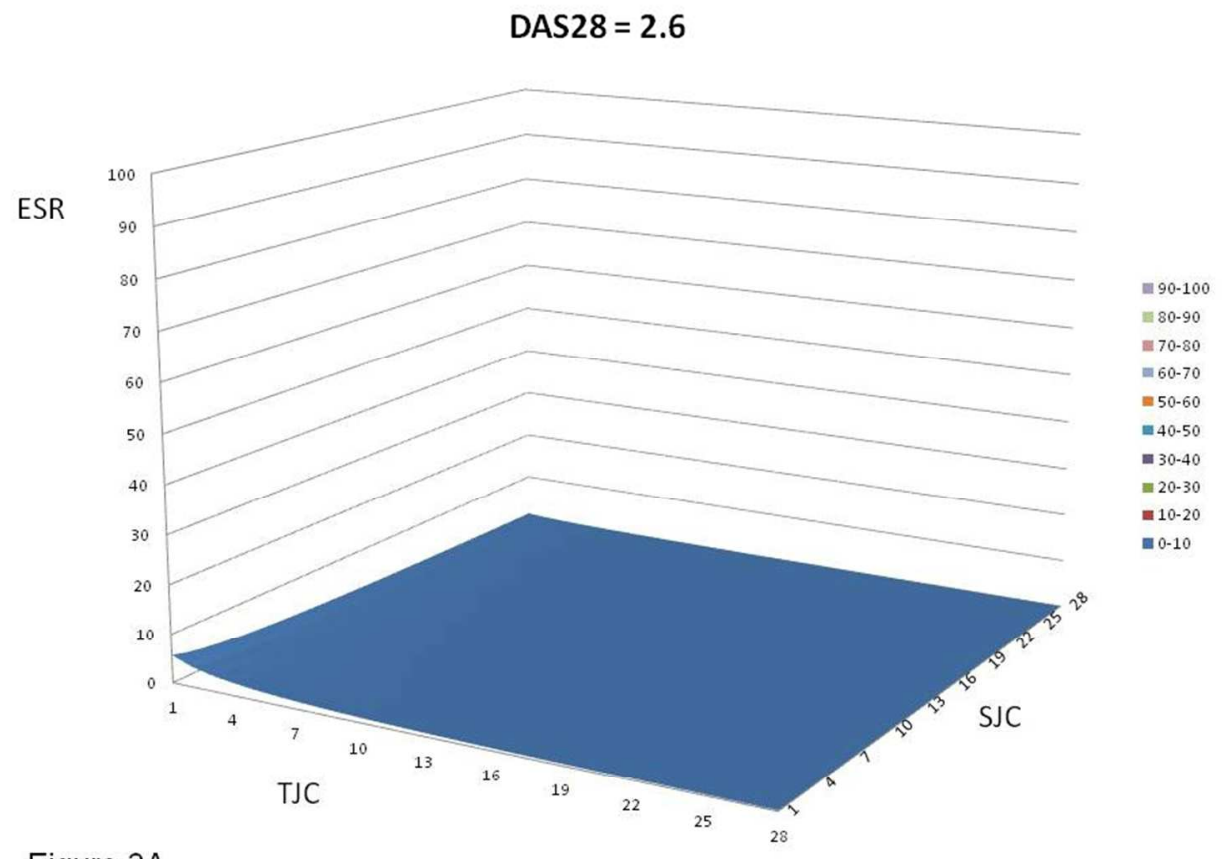

$254 \times 190 \mathrm{~mm}(96 \times 96 \mathrm{DPI})$ 
DAS28 $=2.6$

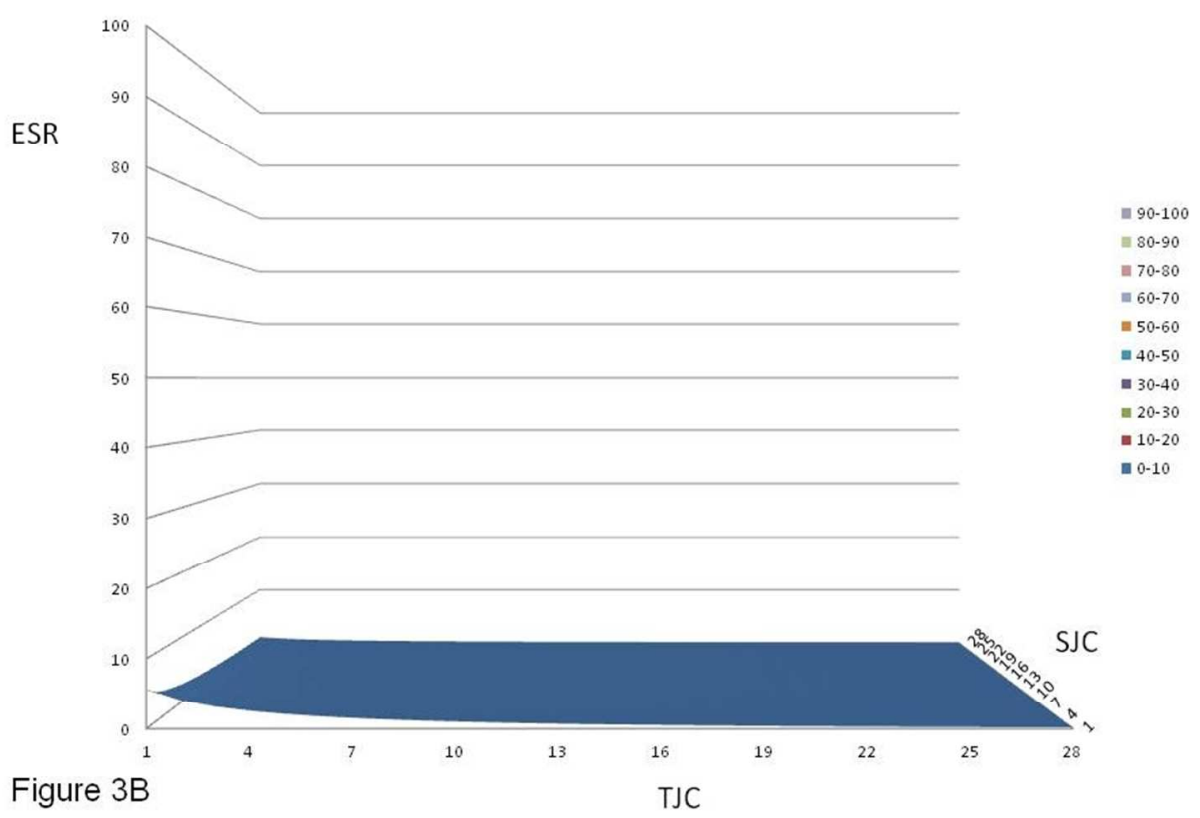

$254 \times 190 \mathrm{~mm}(96 \times 96 \mathrm{DPI})$ 
DAS28 $=2.6$

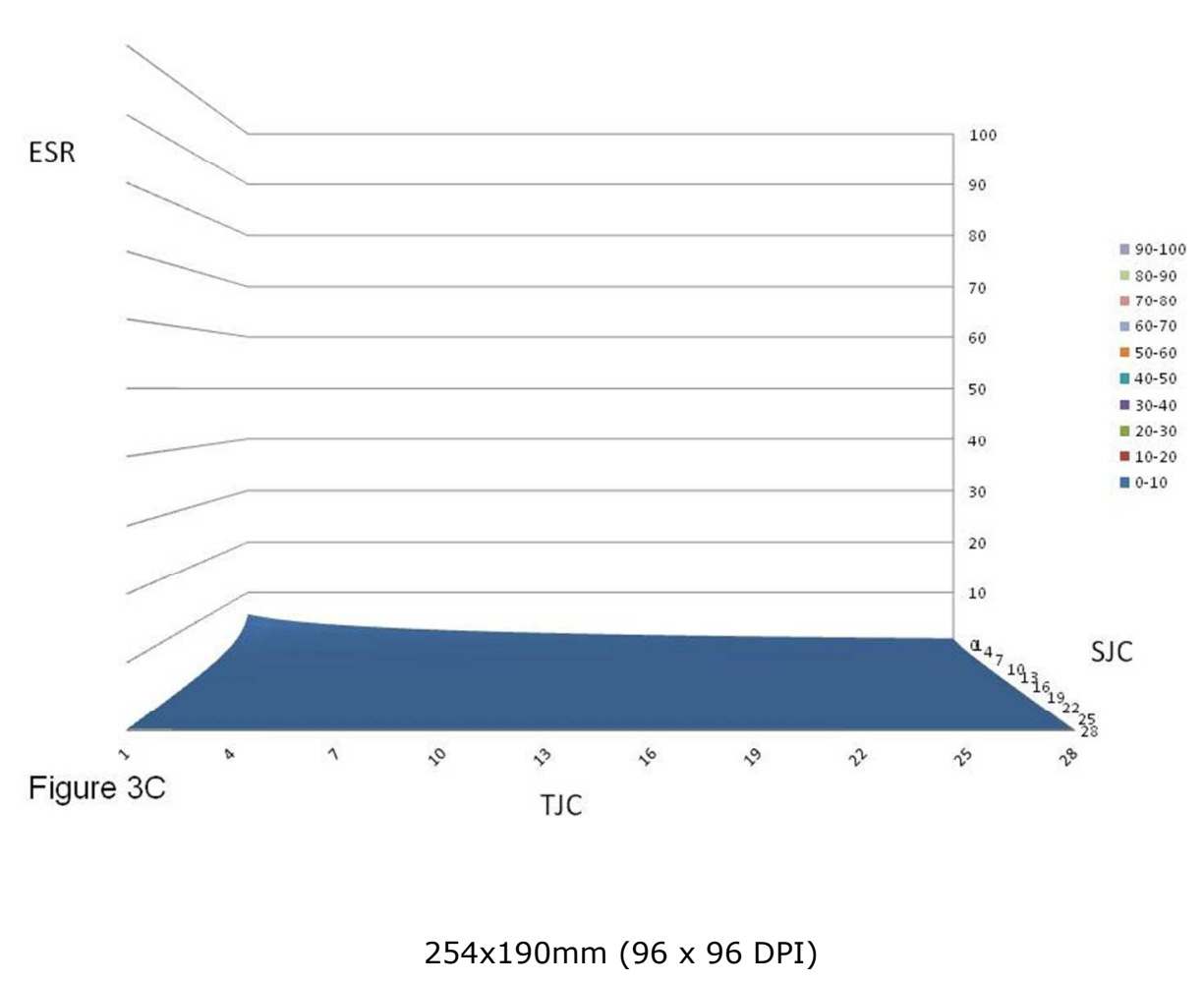


Figure 4

SJC+TJC

$254 \times 190 \mathrm{~mm}(96 \times 96 \mathrm{DPI})$ 
Figure 5

SDAI = 11

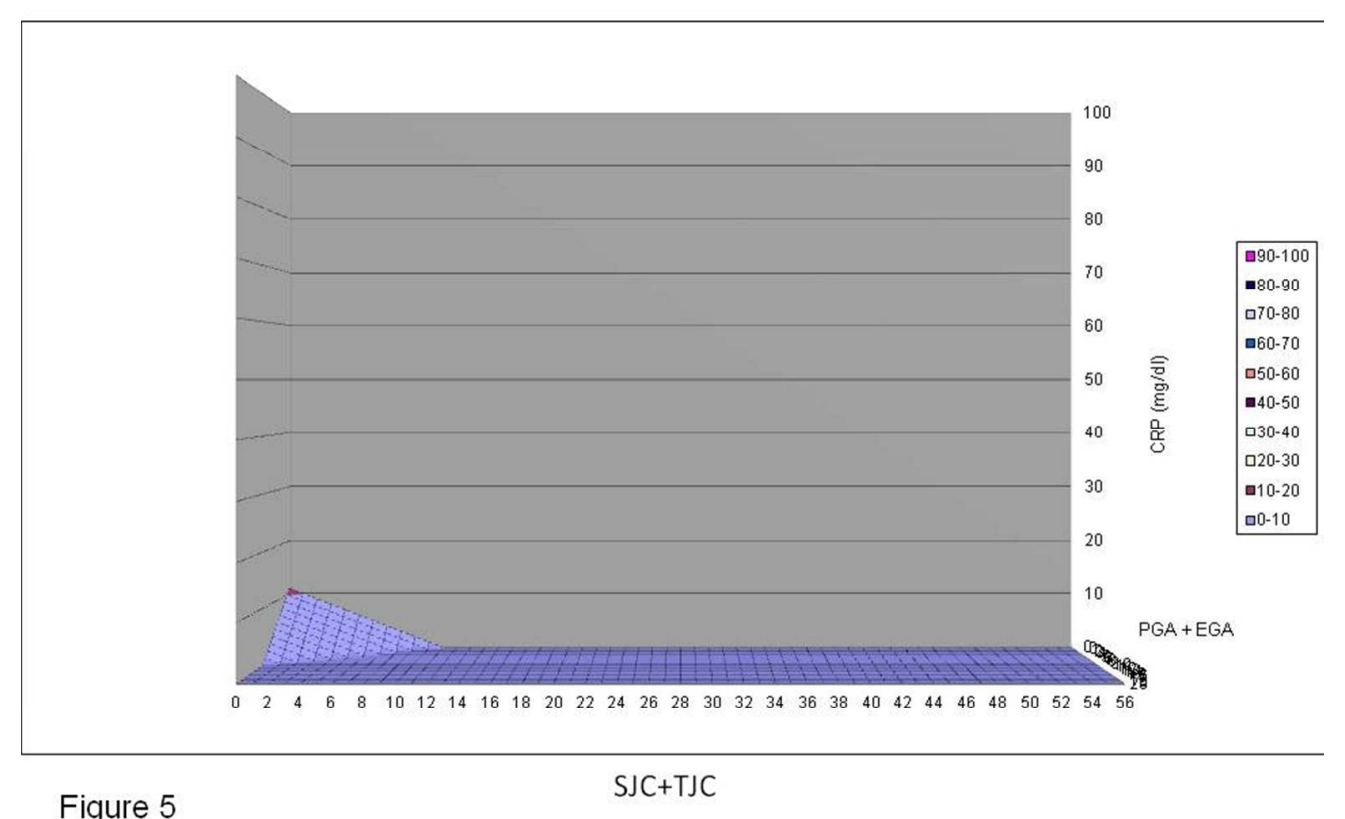

$254 \times 190 \mathrm{~mm}(96 \times 96 \mathrm{DPI})$ 
$\operatorname{SDAI}=\mathbf{3 . 3}$

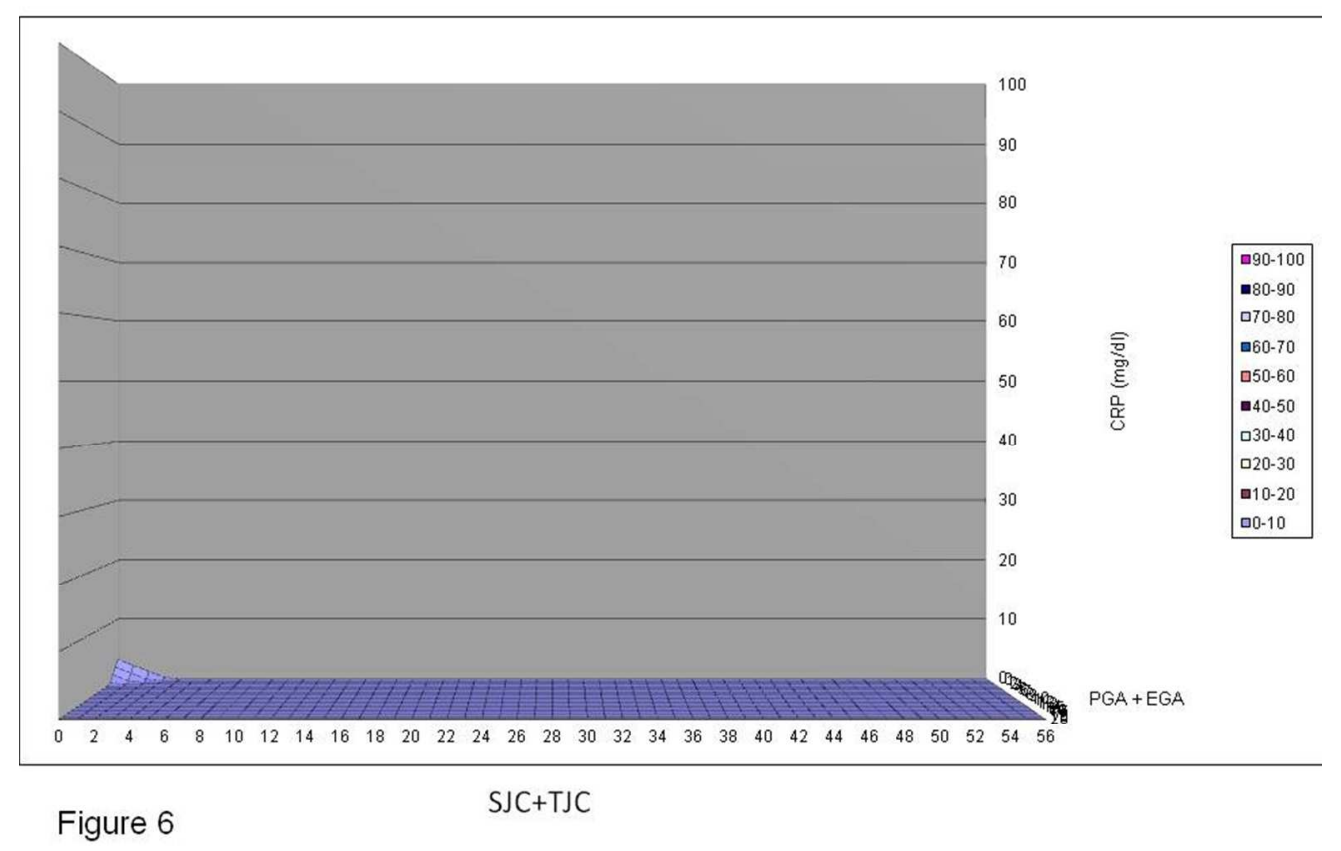

$254 \times 190 \mathrm{~mm}(96 \times 96 \mathrm{DPI})$ 

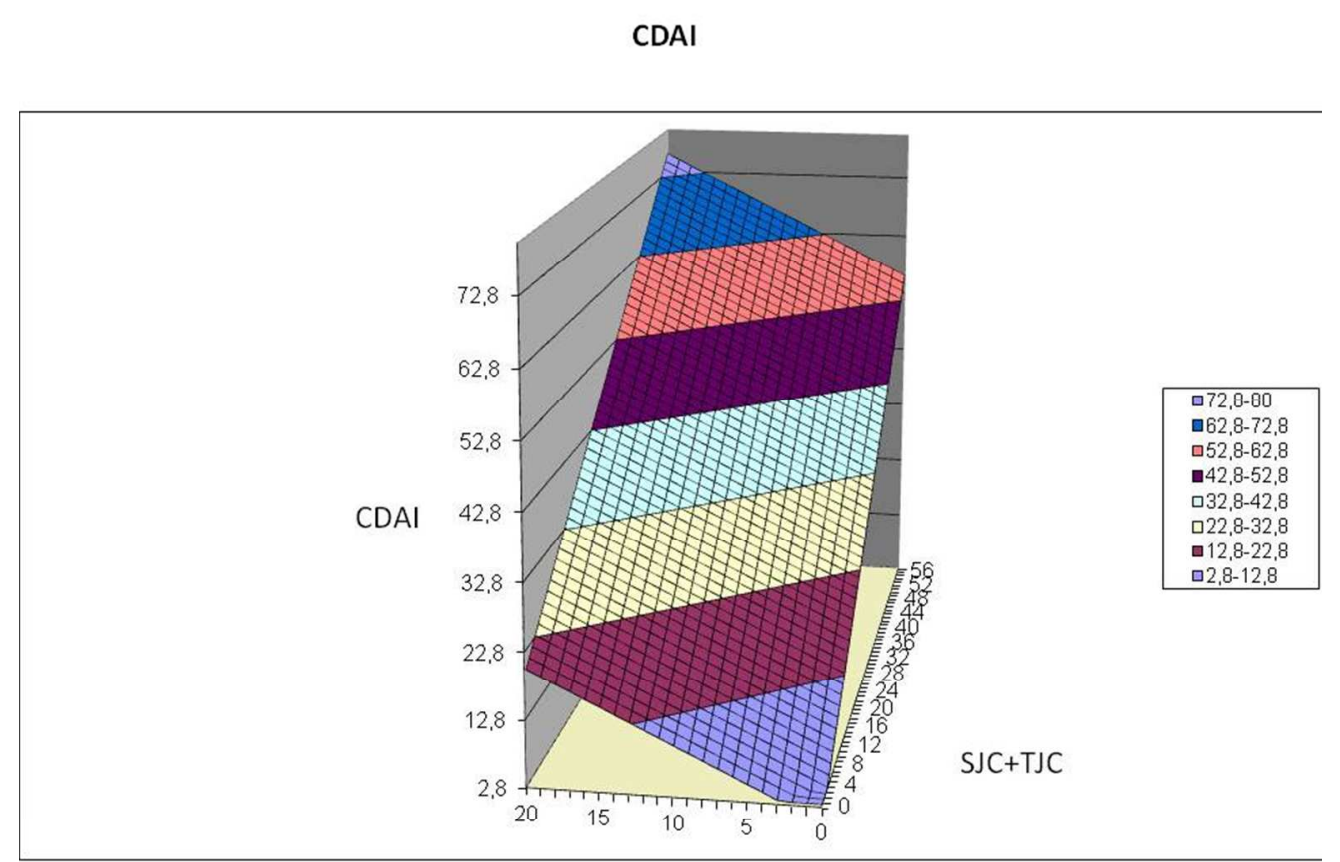

Figure 7A

PGA+EGA

$254 \times 190 \mathrm{~mm}(96 \times 96 \mathrm{DPI})$ 


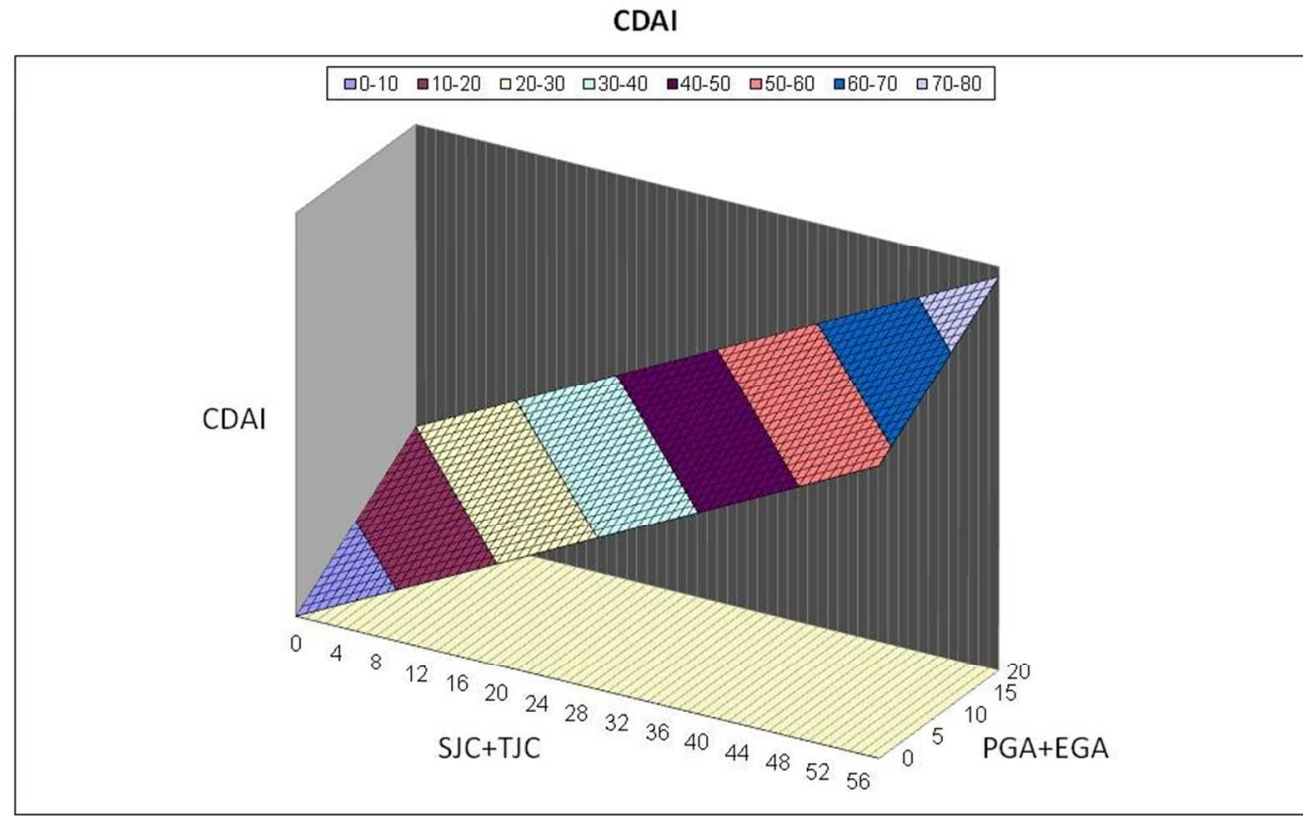

Figure 7B

254×190mm (96 × 96 DPI) 